\title{
Magnetic Nanoparticles for Nanomedicine
}

\author{
Maria Hepel(1) \\ Department of Chemistry, State University of New York, Potsdam, NY 13676, USA; hepelmr@potsdam.edu; \\ Tel.: +1-315-267-2267
}

Received: 8 December 2019; Accepted: 7 January 2020; Published: 9 January 2020

\begin{abstract}
The field of nanomedicine has recently emerged as a product of the expansion of a range of nanotechnologies into biomedical science, pharmacology and clinical practice. Due to the unique properties of nanoparticles and the related nanostructures, their applications to medical diagnostics, imaging, controlled drug and gene delivery, monitoring of therapeutic outcomes, and aiding in medical interventions, provide a new perspective for challenging problems in such demanding issues as those involved in the treatment of cancer or debilitating neurological diseases. In this review, we evaluate the role and contributions that the applications of magnetic nanoparticles (MNPs) have made to various aspects of nanomedicine, including the newest magnetic particle imaging (MPI) technology allowing for outstanding spatial and temporal resolution that enables targeted contrast enhancement and real-time assistance during medical interventions. We also evaluate the applications of MNPs to the development of targeted drug delivery systems with magnetic field guidance/focusing and controlled drug release that mitigate chemotherapeutic drugs' side effects and damage to healthy cells. These systems enable tackling of multiple drug resistance which develops in cancer cells during chemotherapeutic treatment. Furthermore, the progress in development of ROSand heat-generating magnetic nanocarriers and magneto-mechanical cancer cell destruction, induced by an external magnetic field, is also discussed. The crucial roles of MNPs in the development of biosensors and microfluidic paper array devices ( $\mu$ PADs) for the detection of cancer biomarkers and circulating tumor cells (CTCs) are also assessed. Future challenges concerning the role and contributions of MNPs to the progress in nanomedicine have been outlined.
\end{abstract}

Keywords: magnetic nanoparticles; nanocarriers; controlled drug delivery; high-resolution medical imaging; cancer biomarkers; circulating cancer cells; fluorescent probes

\section{Introduction}

Considerable research effort has recently been extended into developing novel nanotechnologies aimed at biomedical advancements [1-11]. This effort has greatly benefited human health and enabled improvements in disease control [12]. In the meantime, nanomedicine created in the process has become a powerhouse of innovative technologies [12,13] for diagnosing, monitoring, and treating the most challenging human diseases, such as neoplasia, neurological disorders, and others. In this comprehensive review, novel applications of magnetic nanoparticles in nanomedicine are evaluated, including those in the area of controlled drug delivery, gene neutralizing or replacement therapy, medical imaging, drug distribution, extenuating drug side effects, mitigating multiple drug resistance, and assisting during invasive medical interventions.

Among the many applications of magnetic nanoparticles (MNPs) in nanomedicine, some of the most interesting are those involving MNPs as probes analyzing the status of the disease and providing drugs to mitigate the problem. MNPs have been successfully utilized in biosensor preparation, fluorescent-magnetic bioimaging probe design, as well as in the synthesis of drug delivery nanocarriers. Specially modified magnetic nanoparticles have also been applied for the detection of cancer and 
circulating tumor cells (CTCs) in addition to the recognition and binding to the cell membrane receptors. Therefore, MNPs have been developed as fluorescent-magnetic probes for cellular/subcellular targeting, imaging and therapy.

Various kinds of magnetic materials can be utilized for MNP development [14,15]. The key challenge is to obtain NPs that are stable in biological environments, are non-toxic, and show the desired magnetic properties. The strong magnets of rare earth elements are not chemically stable in biological media and are cytotoxic [16]. Pure metallic magnets are prone to corrosion. One of the simplest solutions is to utilize iron oxide NPs (magnetite $\mathrm{Fe}_{3} \mathrm{O}_{4}[14,17]$ or hematite $\mathrm{Fe}_{2} \mathrm{O}_{3}[18]$ ) which are non-toxic and highly biocompatible, although their saturation magnetization is not as high as for lanthanide magnetic materials. Small size NPs of this kind are referred to as superparamagnetic iron oxide nanoparticles (SPION). Recently, the Krishnan group reported obtaining monodispersed magnetite nanoparticles with near-ideal saturation magnetization [19]. On the other hand, intermetallic compounds in the transition metal group exhibit quite strong magnetic properties and are relatively stable in biological media. For instance, $\mathrm{Fe}_{\mathrm{x}} \mathrm{Ni}_{\mathrm{y}}$ alloys have been synthesized in form of superparamagnetic nanoparticles [20]. They offer higher magnetization strength than magnetite but are more difficult to synthesize. Very important is the particle size dependence of magnetic properties of MNPs. Larger particles with several magnetic domains often show permanent ferromagnetic properties resulting in MNP aggregation. Smaller particles may form only a single magnetic domain and their superparamagnetic properties are most suitable for the application as MNPs for nanomedicine. It has been shown that particle sizes of approximately 20-30 $\mathrm{nm}$ are critical [14,21,22]. Although the large particles show stronger magnetic properties, they cannot be applied as MNP probes for nanomedicine, due to permanent magnetization leading to MNPs aggregation.

Generally, all MNPs, even the most stable ones, require some kind of a protection against the biological environment [15]. Thus, coatings of MNPs may include silica shells [23], gold film [24], polymer coats [16], or a dense self-assembled monolayer of impenetrable ligands [25].

The MNPs designed for controlled drug delivery and those for targeted activity require immobilization of drugs and targeting ligands on their surface. Hence, these active molecules must be attached to the nanocarrier shell or a surface-protecting film. Various chemistries have been developed to effectively bind these molecules to the nanocarriers [3,8,9,15,26-28]. Other ligands, such as those preventing nonspecific binding of proteins and enhancing biocompatibility must also be incorporated in the surface film of nanocarriers.

\section{Magnetic Nanoparticles (MNP)-Enhanced Sensors for Disease Biomarkers}

In the rapidly growing field of biosensors, the utilization of nanomaterials opens new opportunities for enhancing sensitivity and selectivity of biosensing platforms. Here, magnetic nanoparticles serve two main purposes: (i) to provide convenient means for transferring nanoparticles between different media in sensor fabrication processes, thus facilitating the MNP surface functionalization; and (ii) to serve as a part of the sensory material of biosensors by providing their own functionalized surface for biorecognition of analytes. The optical biosensors based on MNPs have recently been evaluated in an excellent review by Merkoci and coworkers [11]. Different molecular recognition probes and analytes, including disease biomarkers, that can be determined with functionalized MNP-based biosensors have also been reviewed by Krishnan and colleagues [29].

Among the novel biosensors utilizing unique properties of nanomaterials are sensors based on nanophotonic arrays, plasmonic enhancements, and multi-tier amplification schemes. Examples range from optical enhancement by AgNP films [30,31] and plasmon-controlled fluorescence [32-35], to modulation of fluorescence resonance energy transfer (FRET) by protein films on plasmonic NPs [36,37] and a variety of biorecognition processes followed by FRET [38] and intramolecular fluorescence resonance energy transfer (iFRET) [39], resonance elastic light scattering (RELS) [28,40,41], Raman scattering [6,7], or enzymatic detection [42]. The presence of MNPs in sensory films facilitates the 
amplification of biorecognition processes, as evidenced in seminal works on magnetic field-activated sensing of mRNA in vivo [4,5,43].

The enhanced Raman plasmonic grid biosensors based on an Au-coated superparamagnetic $\mathrm{Fe}_{2} \mathrm{Ni}$ nanoparticle core $\left(\mathrm{Fe}_{2} \mathrm{Ni} @ \mathrm{Au}\right)$ have been successfully designed and characterized [20]. These plasmonic-magnetic core-shell NPs have subsequently been employed in SERS studies of DNA damage caused by the chemotherapeutic drug doxorubicin (DOX) [6] (Figure 1) and in designing of a microfluidic platform with a "hot-spot"-enriched and magnetically held SERS nanogrid sensor for the detection of cancer biomarkers [7] (Figure 2). Experimental findings obtained for the carcinoembryonic antigen (CEA) antibody-antigen sandwich structure using NiFe@Au and Au NPs were corroborated by theoretically simulated plasmonic coupling resulting in E-field enhancement based on a core-shell type model with an Au core and protein shell. An excellent CEA detection limit, LOD = 0.1 pM, has been obtained.
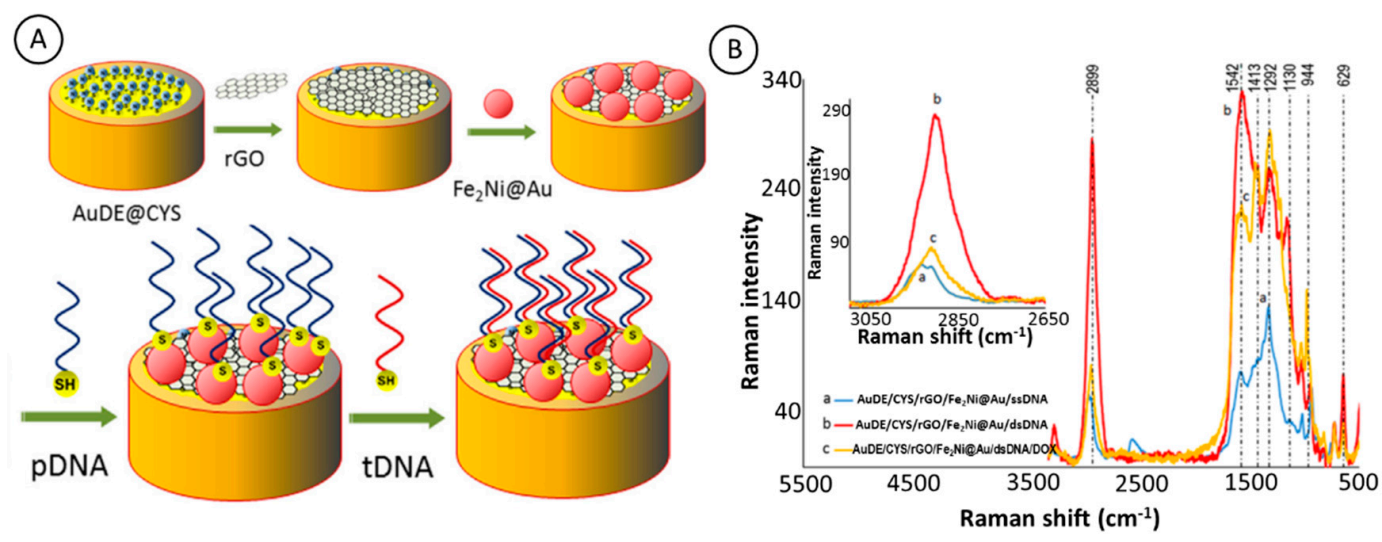

Figure 1. SERS biosensors for testing of doxorubicin (DOX) interactions with DNA. (A) Scheme of the modification of gold disc coated with cysteine (AuDE), reduced graphene oxide ( $\mathrm{rGO}$ ), $\mathrm{Fe}_{2} \mathrm{Ni@Au}$ nanoparticles and probe ssDNA (pDNA) followed by interaction with complementary DNA (tDNA); (B) SERS spectra for (a) nanobiosensor, (b) after hybridization with tDNA, (c) after incubation of dsDNA with doxorubicin (DOX). Inset: details of high frequency peak. Reprinted with permission [6].

(A)

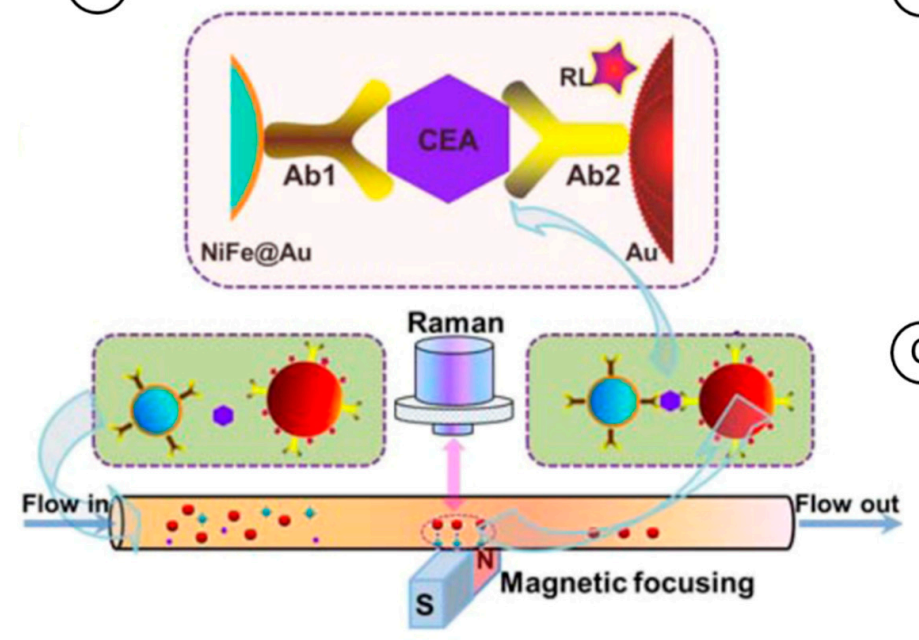

(B)

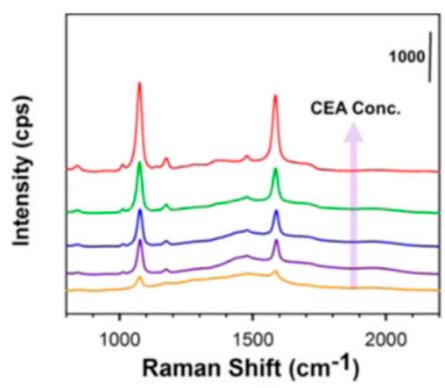

(C)

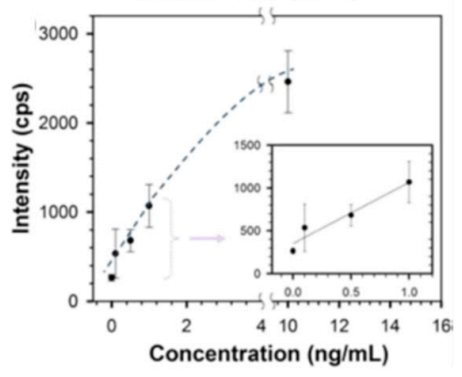

Figure 2. (A) Scheme of experimental setup; (B) SERS spectra of sandwich conjugates of NiFe@Au and AuNPs with antibodies, in response to the different concentrations of CEA $(0.0,0.1,0.5,1.0$, $10.0 \mathrm{ng} / \mathrm{mL}$ ); (C) plot of peak intensity at $1076 \mathrm{~cm}^{-1}$ vs. CEA concentration. Insert: a magnified view of the low-concentration range data. Reprinted with permission [7]. 
Experimental and theoretical assessments of the high field spots formed in the interparticle area in a particle dimer bound via DNA duplex linkages have recently been performed for Au- or Ag-coated magnetite SPIONs [24].

Magnetic nanoparticles have also been employed in high-sensitivity hyphenated analytical methods. A combination of: (i) cell labeling with multiple magnetic metal beads; (ii) hybridization chain reaction amplification; and (iii) detection using inductively coupled plasma-mass spectrometry (ICP-MS), has been proposed by He et al. [44] for distinguishing and simultaneous counting of multiple cancer cells. The labelling of cells with MNPs was described by Kolosnjaj-Tabi et al. [45]. This technique was applied for simultaneous counting of human hepatocellular carcinoma cells (SMMC-7721) and human lung carcinoma cells (A549) with high sensitivity and specificity. Simultaneous detection of CTCs and cancer biomarkers in an immunomagnetic flow system was first described by Huang et al. [46].

\section{MNP-Core Nanocarriers for Controlled Drug and Gene Delivery}

Various types of nanocarriers have been investigated for possible application in theranostics, including plasmonic metal NPs, liposomes, micelles, protein nanostructures, graphene oxide nanosheets, biopolymers, synthetic polymers, and others [8-10,26,27,47,48]. These nanocarriers must combine a high capacity for carrying drugs or genes, biocompatibility-enhancing agents, and targeting ligands able to recognize the sites for a drug release (e.g., receptors in a cancer cell membrane). The same requirement concerns nanocarriers for gene delivery where an oligonucleotide strand is immobilized on a nanocarrier in place of drug molecules $[10,28,47,49]$. The nanocarriers must also be able to release the drugs under specific local conditions (acidity, GSH level) [50-52] or under external stimuli, such as a light pulse, an X-ray signal, or a heat wave. The novel nanocarriers now include also functionalized magnetic core-based NPs [3,6,7,53-55], where the magnetic core is protected against degradation in biological environments by coating with a silica shell [23], gold film [24], a tight polymeric coat (e.g., PEG, poly-L-lysine, carboxydextran) [16], or a dense self-assembled monolayer of impenetrable ligands [25]. The protective shell provides also an easy means for the attachment of drugs, adjuvants, targeting ligands, and agents ensuring the nanocarrier biocompatibility [53,54,56]. The magnetic properties of such carriers enable magnetic field-based guidance of nanocarriers to the target tissue. Recently, the magnetic actuation of a drug release at the target sites has been proposed [5,43].

The effects of particle surface corona on cancer cell targeting were investigated in simulated physiological fluids by Zhao et al. [57]. Studies of advanced cancer cell targeting have been carried out by many research groups $[15,58]$ and an interesting range of suitable chemistries, including "click chemistry", has been devised.

Further issues in controlled drug delivery are related to the nanocarriers internalization, i.e., entering into a target cell, either by endocytosis, receptor-mediated entry (e.g., via binding to folate receptors), or by penetrating the cell membrane (for hydrophobic nanocarriers, e.g., graphene or graphene oxide nanocarriers that partially dissolve in the membrane disrupting its tightness). The same mechanisms as observed for other types of solid nanocarriers, are expected for MNP-based nanocarriers.

The drug and gene release from MNP-based nanocarriers is also expected to be similar to other solid nanocarriers because binding of these ligands to both types of nanocarriers are of the same type.

\section{Magnetic Particle Imaging (MPI) for Cancer Diagnostics, Staging, and Medical Intervention}

Magnetic Particle Imaging (MPI) is a novel non-invasive and radiation-free tomographic technique where in contrast to X-ray computed tomography (CT) and magnetic resonance imaging (MRI), the imaging is performed by tracking the superparamagnetic iron oxide nanoparticle (SPION) tracers with simultaneous generation of 3D images with extraordinary spatial and temporal resolution [59]. The direct 3D volume rendering (DVR) enables real-time 3D guidance in vascular interventions, such as in the real-time percutaneous transluminal angioplasty [60,61] with the insertion of a stent or balloon in a blocked artery. It can also be utilized for the direct visualization of thromboembolic material within the lumen of the middle cerebral artery (MCA), carotid arteries, or a hepatic artery [62]. 
The first commercial preclinical MPI scanners, with small chambers able to accommodate a mouse or rabbit, have recently been developed and are under testing. A new scanner with large field of view (up to $45 \mathrm{~mm}$ ) with a resolution to $500 \mu \mathrm{m}$, based on a traveling wave MPI and an array of electromagnets enabling magnetic field gradients up to $10 \mathrm{~T} / \mathrm{m}$, has recently been announced by the Vogel group [2,63]. A human-sized MPI research system for brain applications has been designed by Graeser and colleagues [1]. First MPI angiography in human-sized organs (pig kidney perfusion system) has been obtained by Molwitz and coworkers [64]. The principles and applications of MPI in biomedical research have been evaluated in a review by Talebloo and coworkers [65].

The effect of the magnetic nanoparticle core size on the MPI sensitivity has been investigated by Shasha et al. [66]. They have demonstrated that the magnetic core diameter of SPION nanoparticle tracers of $28 \mathrm{~nm}$ is optimal for use in MPI. For larger NPs, the relaxation effects and interparticle interactions begin to dominate, reducing the colloid stability. The optimized SPION probes were applied in studies of their intracellular dynamics for MPI applications [67]. The monodispersed single-phase magnetite NPs have been well characterized and size-optimized for MPI [21,22]. The utilization of MPI for in-vivo cancer imaging with systemic tracer administration was reported by Collony's group [68] (Figure 3). A whole-body biodistribution of the tracer NPs was monitored with a large field of view (FOV). Another scanner, with decoupled harmonics generation and field-free point handling, was recently reported by Bagheri and coworkers [69]. Harmonics are generated due to the non-linear magnetization characteristics of tracer MNPs. This new approach provides more flexibility for exploring and optimizing tracer particle responses to obtain the best spatial resolution of images in the sub-millimeter range.

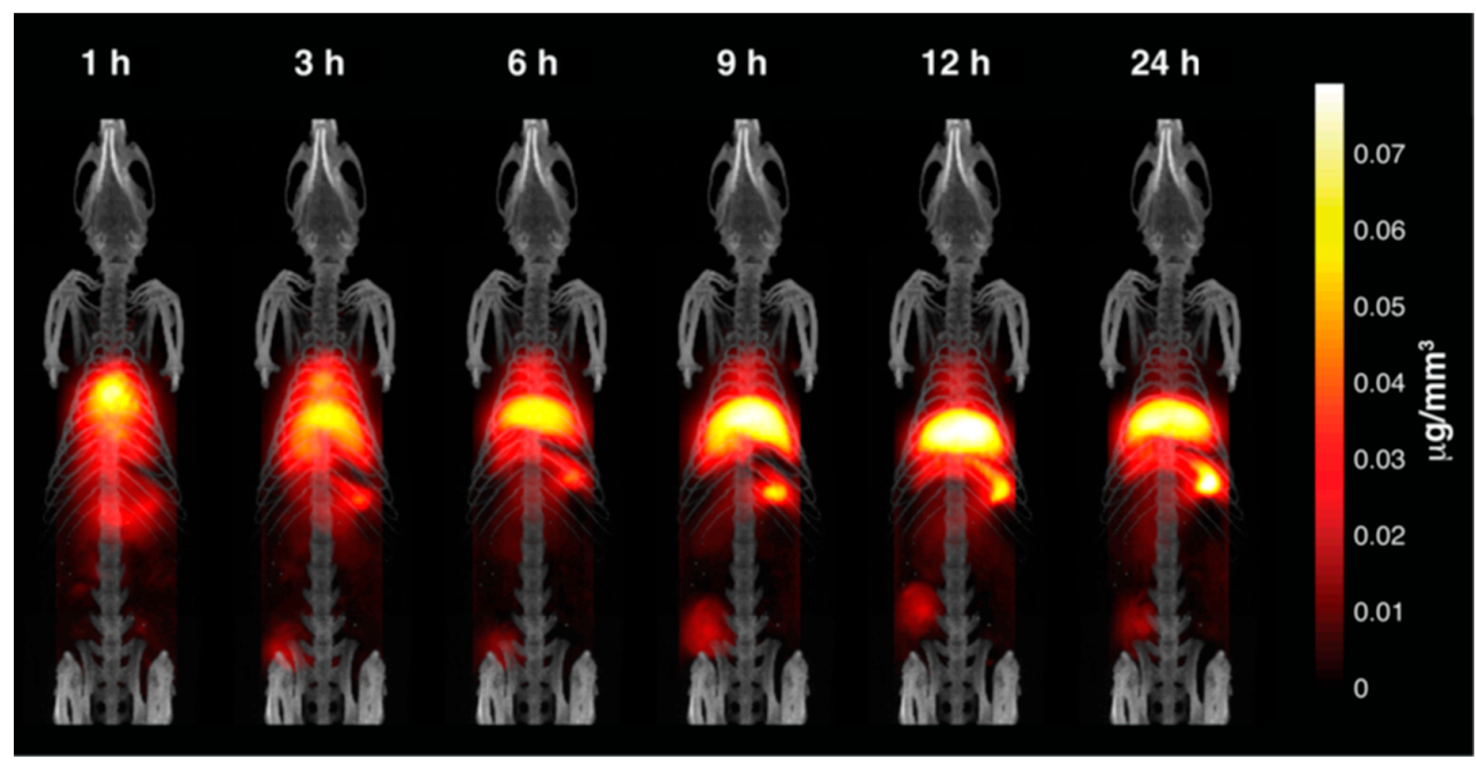

Figure 3. Maximum intensity projection of 3D magnetic particle imaging (MPI) volumes co-registered with a CT skeletal reference. The whole-body tracer dynamics along with the tumor are clearly visualized. Reprinted with permission [68].

The non-targeted MPI can be utilized for cancer detection and therapy due to the enhanced permeability and retention (EPR) effect caused by leaky blood vessels, poor drainage of lymphatic system, and misalignment of endothelial cells.

So far, the outstanding performance of the MPI scanning technique has been demonstrated in the following applications [70]:

- vasculature visualization and monitoring of blood flow;

- detection of neoplasia and monitoring of outcomes of therapeutic intervention;

- detection of arterial aneurisms; 
- guidance for catheterization in percutaneous angioplasty, including procedures performed during cardiac infarction;

- cancer thermotherapy.

Research studies on the utilization of MPI techniques in other fields of nanomedicine are under way.

In summary, the novel MPI technique based on magnetically tracking SPION probes offers very high spatial and temporal resolutions, is radiation-free, depth-independent, and causes virtually no side-effects. Therefore, it can successfully compete with the well-established imaging techniques, such as MRI, CT, and PET. Also, MPI does not require allergenic and highly nephrotoxic iodine-based contrast agents [71]. Note that Schlorf and coworkers [72] have used the SPION nanoparticles as the contrast agents and as the labels for cell tagging for MRI imaging. They have found that the retention of the magnetic nanoparticles in cells lasts for about two weeks.

The utilization of superparamagnetic iron oxide nanoparticles in conjunction with the new MPI technique has the potential to detect and diagnose cancer at an earlier stage than current imaging methods [3].

\section{Hyperthermic Treatment of Malignant Cells with MNPs}

Hyperthermia has been applied as a method of anticancer therapy, in which nanoparticles highly absorbing electromagnetic radiation are administered to the cancer tissue and then excited with a precision laser beam to destroy cancer cells by the rising temperature of the nanoparticles. For nanocarriers with a magnetic core, the temperature rise can also be achieved by vibrating or rotating the nanocarriers via stimulation by alternating magnetic field [73-78]. It has been successfully applied for treatment of malignant glioma [79]. The advantage of using MNP carriers is clear in the deep penetration of magnetic field modulation stimulating the nanocarriers, whereas light stimulation is applicable only to a near-surface tissue.

Wu et al. [80] have successfully synthesized porous carbon-coated magnetite nanoparticles (PCCMNs) by a one-pot solvothermal method. A hyaluronic acid-modified PCCMN with fluorescent carbon quantum dots has been applied for efficient photothermal cancer therapy (PTT) in vivo with MRI monitoring and fluorescent imaging. The nanocarriers served both as the contrast agent for MRI and the heat generator upon absorbing a NIR laser beam at $808 \mathrm{~nm}$ wavelength and $1.5 \mathrm{~W} / \mathrm{cm}^{2}$ energy. The proposed nanocarriers can also carry chemotherapeutic drugs.

A new drug delivery system based on magnetic hollow porous carbon nanoparticle nanocarriers (MHPCNs) was also developed by the same group [81]. To cap the pores in the nanocarrier shell, a poly $\left(\gamma\right.$-glutamic acid) was used. The photothermal conversion of carbon and magnetite $\left(\mathrm{Fe}_{3} \mathrm{O}_{4}\right)$ shells enabled photothermal therapy to be performed with no anticancer drug leakage during the systemic distribution. The proposed drug delivery in sealed nanocages and controlled photothermal release enabled the multidrug resistance induced by chemotherapeutic treatment to be overcome $[82,83]$. The MPI was not used in these experiments. Therefore, monitoring of the therapeutic outcomes was limited to the resolution of the magnetic resonance imaging. These experiments have demonstrated the effective tumor growth inhibition through the hyperthermia/chemotherapy synergistic action.

The conditions for efficient heat generation have been discussed by many researchers and high-performance frequency tuners for resonant inverters suitable for magnetic hyperthermia have been designed [84].

\section{Magneto-Mechanical Destruction of Cytoskeletal Scaffolds and Permeabilization of Lysosome Membranes by Alternating Magnetic Field-Driven MNP Vibrations for Cancer Treatment}

Alternating magnetic field-driven vibration and rotation of MNPs accumulated in cancer cells may result in relaxation with heat generation resulting in local temperature increase, as discussed in the case of hyperthermia. However, for small MNPs, generally less than $20 \mathrm{~nm}$ in diameter, magnetic field stimulation would not result in enough heat generation to cause sufficient temperature increase to kill cancer cells [74]. Yet, in experiments performed by several groups, the magnetic 
field-driven MNP vibrations clearly resulted in cancer cell death [18,85-92]. Recently, Kabanov's group [93] provided a completely new mechanism of cancer cell death under such conditions. Their experiments, conducted with 7-8 nm MNPs and a low-frequency magnetic field of $50 \mathrm{~Hz}$, confirmed no temperature rise of the medium. They demonstrated that the cancer cell killing ability of this low energy magnetic stimulation is due to the disruption of the cytoskeletal framework of cancer cells by magneto-mechanical movement and inelastic impact of MNPs leading to apoptosis. Klyachko et al. [91] and Hoffmann et al. [94] have found that magnetic field-driven MNPs can be used to control enzymatic processes. Further studies of the discovered phenomenon will help to uncover biochemical pathways driving the cells to self-destruction.

\section{Magnetically Guided MNPs for ROS Generation and Cancer Treatment}

Reactive oxygen species (ROS) are highly potent radicals able to damage DNA, lipids and other biomolecules. They are generated in the mitochondrial respiration system and used by the organism to protect against invasion of microbes. The generation of ROS may also be utilized in the fight with cancer. Hence, this concept has recently gained new attention [95-101] which concentrates on enhancing the ROS generation in mitochondria with various drugs and in Fenton-like cascade processes based on decomposition of $\mathrm{H}_{2} \mathrm{O}_{2}$ to $\mathrm{HO}^{*}$ radicals, catalyzed by $\mathrm{Fe}^{2+}$ or $\mathrm{Cu}^{2+}$ and catechol moiety [102]. Cell death caused by ROS generation by Fenton-like cascades has been dubbed oxytosis [97] or ferroptosis [95]. Unlike a typical apoptosis, it is not driven by the caspase 3 pathway and does not lead to chromatin condensation [97].

A new kind of interesting magnetic nanoparticles, consisting of a magnetic iron carbide $\mathrm{Fe}_{5} \mathrm{C}_{2}$ (MIC NP), has been developed by Yu and coworkers [103]. These MIC NPs are able to release $\mathrm{Fe}^{2+}$ ions upon entering the zone of high acidity in the tumor environment. Since $\mathrm{Fe}^{2+}$ ions catalyze the decomposition of $\mathrm{H}_{2} \mathrm{O}_{2}$ through the Fenton cascade mechanism and since $\mathrm{H}_{2} \mathrm{O}_{2}$ is overproduced and available in cancer cells, the reactive oxygen species, in particular $\mathrm{HO}^{*}$ radicals, are formed and aid in the destruction of cancer cell DNA [102]. To enhance the release of $\mathrm{Fe}^{2+}$ ions from MIC NPs, a coating of a magnetite film on $\mathrm{Fe}_{5} \mathrm{C}_{2}$ core was applied, forming the final MIC NPs with the composition: $\mathrm{Fe}_{5} \mathrm{C}_{2} @ \mathrm{Fe}_{3} \mathrm{O}_{4}$. A schematic illustration of the MIC NP endocytosis, followed by $\mathrm{Fe}^{2+}$ release and ROS generation is presented in Figure 4, together with T2-weighted MR images of 4T1 tumor-bearing mice. Monitoring of MIC NPs distribution can be carried out using a magnetic resonance imaging (MRI) scanner. Interestingly, it has been found that the magnetism of MIC NPs decreases upon $\mathrm{Fe}^{2+}$ release and the T2 signal in MRI decreased. At the same time, the released $\mathrm{Fe}^{2+}$ causes the increase in the T1 MRI signal. Therefore, the presence of a tumor tissue with a low $\mathrm{pH}$ and the release of $\mathrm{Fe}^{2+}$, leading to the generation of ROS and apoptosis of cancer cells, can be sensitively monitored by MRI. 

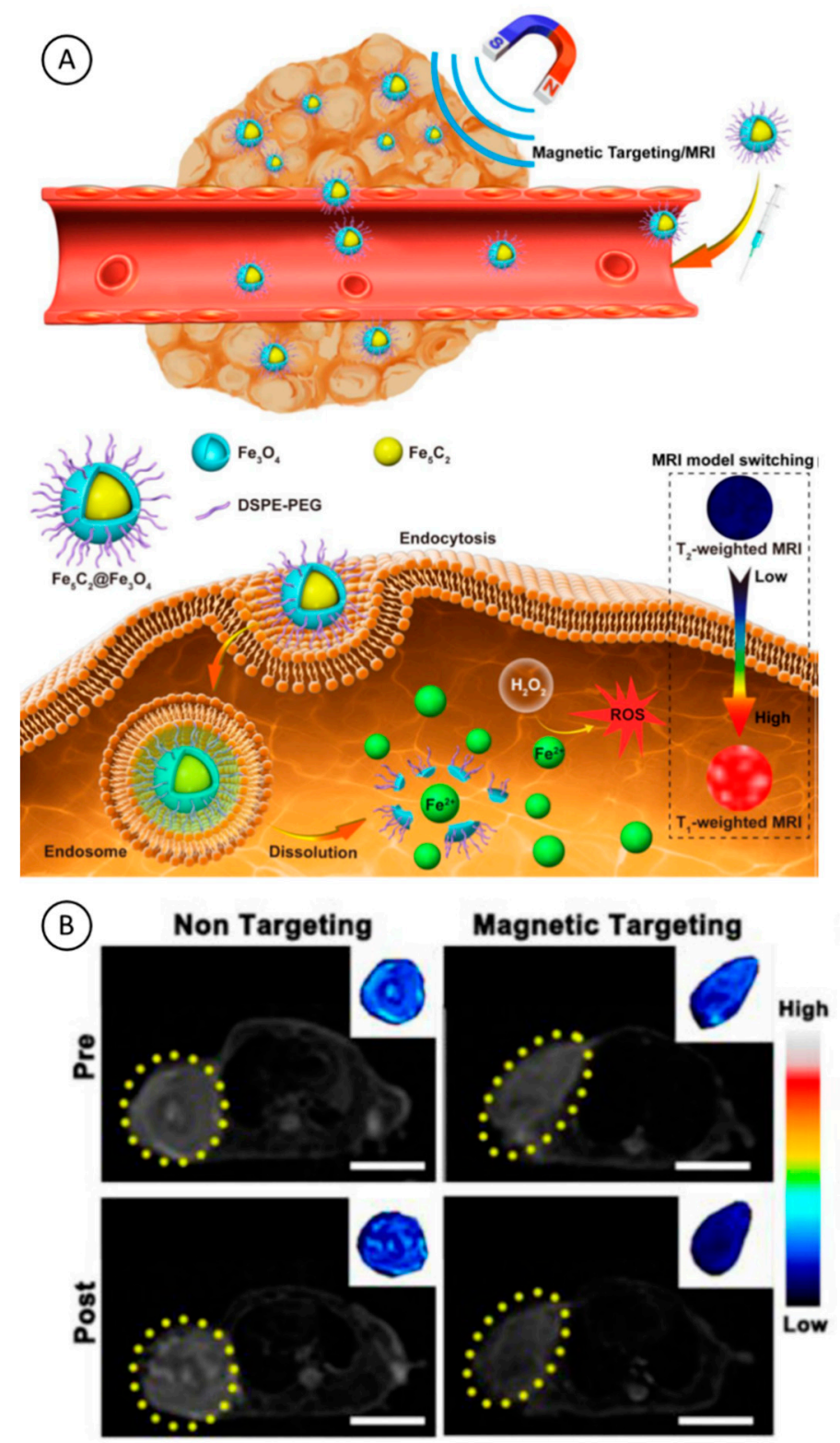

Figure 4. (A) A schematic illustration of MNPs for $\mathrm{pH}$-responsive $\mathrm{Fe}^{2+}$ releasing, ROS generation and $\mathrm{T} 2 / \mathrm{T} 1$ signal conversion; (B) representative T2-weighted MR images of 4T1 tumor-bearing mice before (Pre) and one day after (Post) injection of PEG/Fe $\mathrm{C}_{2} @ \mathrm{Fe}_{3} \mathrm{O}_{4} \mathrm{NPs}$ with or without magnetic targeting. The tumor sites are circled by a yellow dashed line. Reprinted with permission [103].

Applications of high-frequency alternating magnetic fields (HF-AMF) with MNPs accumulated in tissues [90] have demonstrated permeabilization of lysosome membranes in cancer cells but not in healthy cells. The appearance of ROS, generated in mitochondria, was detected $30 \mathrm{~min}$ after the AMF application. These experiments show that using MNPs stimulated with HF-AMF, it becomes possible to generate ROS in targeted cancer cells, mitigating collateral damage to healthy cells as well as reversing drug resistance established by overexpression of GSH in cancer cells in response to oxidative stress $[41,104,105]$ introduced by chemotherapeutic drugs.

\section{Detection of Circulating Cancer Cells}

In the critical stage of tumor development, some cancer cells begin to detach from the original neoplasia and enter the blood stream and lymphatic highway system to become circulating tumor cells (CTCs), able to settle on the way and proliferate into new tumor outcrops, marking the onset of 
metastasis, i.e., the spread of the original tumor into distal sites. The detection of CTCs is therefore an important and challenging task in cancer therapy. The key issue is the low concentration of CTCs. Hence, special efforts have been made to develop highly sensitive techniques for the detection and identification of CTCs. So far, the microfluidic format of CTCs isolation and identification is the only format that can offer successful outcomes and rapid analysis without sample preparation. It integrates all procedures in a small microfluidic chip and requires minimal sample volume, as envisioned by the device inventors [106].

In one such effort, Green et al. [107] have designed a microfluidic device for high-sensitivity profiling of CTCs in patients with metastatic castration-resistant prostate cancer (mCRPC). The circulating cells were first sorted according to protein expression levels. For that purpose, EpCAM antibody-functionalized magnetic nanoparticles were developed. The blood samples analyzed were from patients undergoing treatment with abiraterone or enzalutamide, two drugs used to treat advanced prostate cancer. The samples taken during treatment (9-22 weeks) were compared to the baseline (week 0). It has been shown that the number of low-EpCAM CTCs increased with the treatment time for progressive patients. The proposed microfluidic device with antibody functionalized MNP probes offered higher efficiency compared to the commercially available CellSearch device.

Mandal et al. [108] have developed AIEgen-based fluorescent magnetic nanoparticle probes, with a hydrodynamic size ranging from 25 to $50 \mathrm{~nm}$ and rich surface chemistry enabling attachment of ligands able to recognize and bind to cell membrane receptors. The AIEgen molecules exhibit a unique aggregation-induced fluorescence emission (AIE) property. To construct the MNP@AIEgen probes, the hydrophobic $\gamma-\mathrm{Fe}_{2} \mathrm{O}_{3}$ nanoparticles were first converted into hydrophilic nanoparticles by a polyacrylate overcoat of N-(3-aminopropyl)-methacrylamide hydrochloride with/without 3-sulfopropyl methacrylate. The obtained primary amine-terminated hydrophilic nanoparticles were then conjugated with tetraphenylethene (TPE), an AIEgen molecule, further derivatized with various functional groups. The study's authors have demonstrated that the AIEgen-based fluorescent MNPs can act as the cellular imaging probes. Furthermore, the labeled cells can be magnetically separated.

An immunomagnetic flow system for simultaneous detection of CTCs and cancer biomarkers in blood was developed by Huang et al. [46]. In his microfluidic device, folate receptors (FR) in membrane of cancer cells were detected using fluorescence microscope while cells marked with anti-FR antibody-coated magnetic beads were captured with a magnetic field on the microfluidic channel wall. Using a microfluidic device with magnetic separation of CTCs and electric impedance cytometry, Han and Han [109] were able to detect colorectal cancer cell line DLD-1 in peripheral blood by enrichment of ca. 500-fold. Recently, Wang and coworkers [110] have developed a rapid and highly efficient method to isolate and identify heterogeneous CTCs (F-MNPs+, Hoechst 33342+, and CD45-) from patient blood samples using fluorescent MNPs (F-MNPs). An F-MNP consisted of a $\mathrm{Fe}_{3} \mathrm{O}_{4}$ core and a SiO ${ }_{2}$ shell decorated with a fluorescent dye 1,1'-dioctadecyl-3,3,3', $3^{\prime}$-tetramethyl-indocarbocyanine perchlorate (DiI). On the surface of F-MNPs, a layer of a zwitterionic polymer, poly(carboxybetaine methacrylate) (pCBMA), able to decrease the nonspecific cell adhesion with anti-EpCAM and anti-N-cadherin antibodies, was formed (Figure 5). 


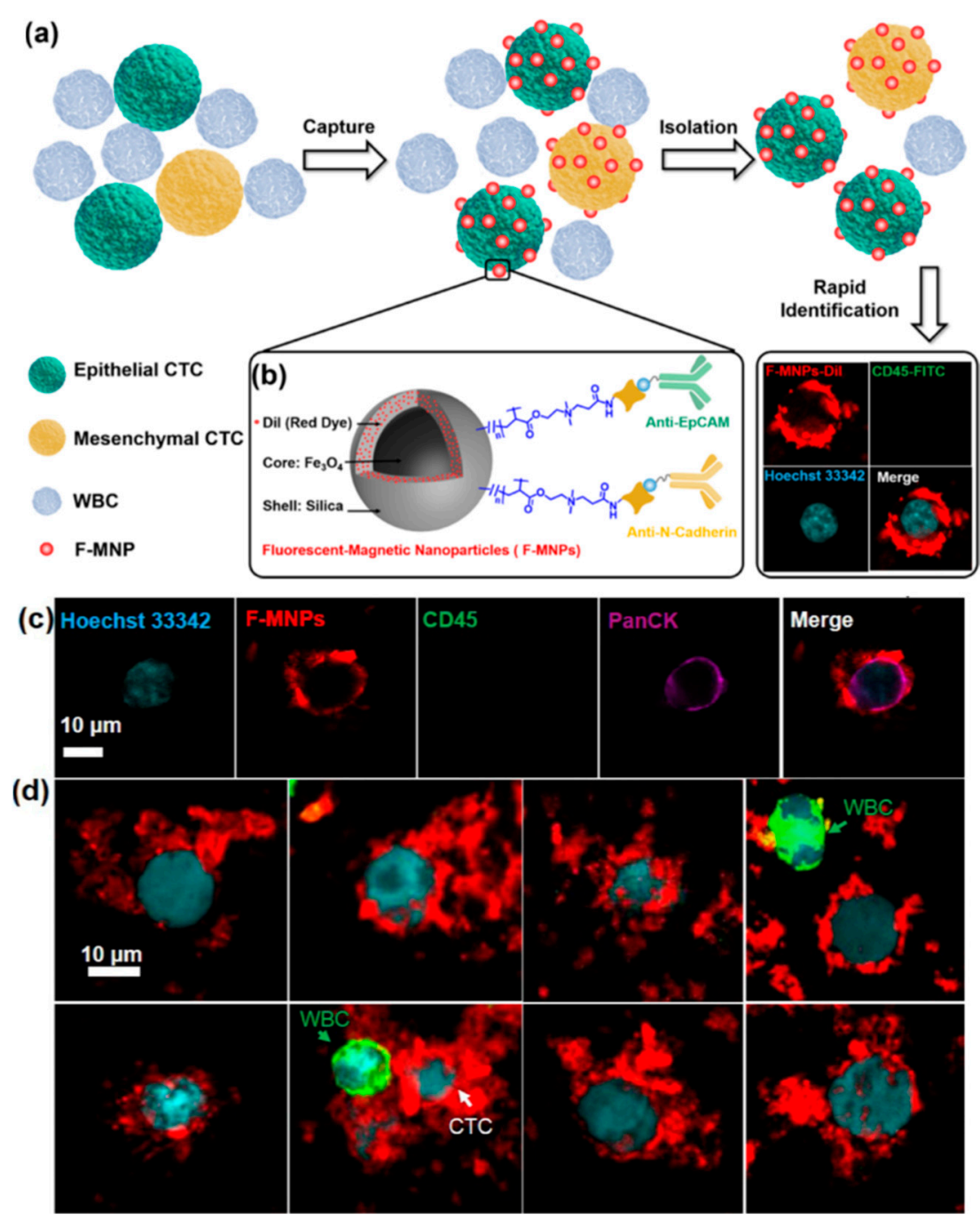

Figure 5. (a) Illustration of the isolation and identification of heterogeneous circulating tumor cells (CTCs) from breast cancer patients' blood samples using fluorescent magnetic nanoparticles (F-MNPs); (b) the construction of F-MNPs; (c) fluorescent images of one CTC identified by immunostaining of anti-PanCK-647 and F-MNPs for breast cancer sample BrC01; (d) fluorescent images of eight CTCs (Hoechst 33342+, F-MNPs+, CD45-) and WBCs (Hoechst 33342+, CD45+) from the BrC05 patient sample identified by F-MNPs with immunostaining of anti-CD45-FITC and Hoechst 33342. Reprinted with permission [110].

\section{Protective Coating of MNPs}

Magnetic nanoparticles operating in a biological environment generally require a protective coating against adverse effects of dissolved oxygen, ROS, and bioactive compounds. Hence, compact and chemically stable shells are grown on the cores. Biomedical applications require robust MNPs that are properly coated by hydrophilic polymers. Firstly, surface coatings are important to prevent MNPs from agglomeration in a physiological environment. Therefore, the MNP coatings have to show a net non-zero charge and have limited zwitterionic and hydrophobic properties. Secondly, coatings must act as a barrier, effectively shielding the magnetic core against the attack of chemical species in the aqueous solution. A silica shell or gold film can fulfill these requirements, but a tight polymer shell is also suitable for this purpose. Further functionalization of the shell material should be considered to avoid non-specific adsorption of biomolecules. Thirdly, different functional groups can be attached to the coatings (e.g., amine, carboxyl) that can be used for immobilization of functional molecules, 
such as drugs, adjuvants, targeting ligands, fluorescent molecules, biocompatibility enhancing agents, and molecules preventing non-specific adsorption [8,27,48,111] (Figure 6).

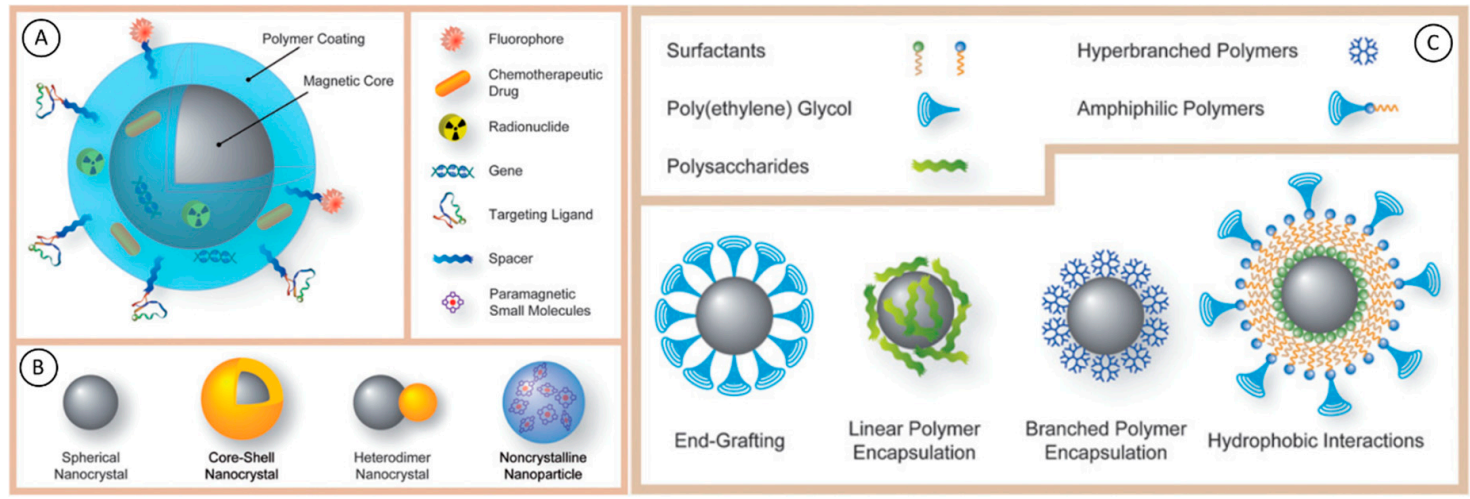

Figure 6. (A) Illustration of the structure of a multifunctional/multimodality MNP with a magnetic core, a polymeric coating, and targeting ligands extended from the surface of MNP with the aid of polymeric spacers; (B) schematic representation of different types of magnetic cores; (C) illustration of different types of coating strategies for hydrophilic MNPs. Reprinted with permission [111].

\section{Toxicity of MNPs and Systemic Clearance}

The protected core-shell MNPs are generally nontoxic and are well tolerated in vivo, independently of the administration routes. However, the toxicity of newly developed MNPs should always be carefully evaluated. For instance, Feng et al. [112] have performed a detailed investigation of the in vitro cell uptake and cytotoxicity, as well as the in vivo distribution, clearance and toxicity of commercially available and well-characterized iron oxide nanoparticles (IONPs) with different sizes and coatings. It has been found that the polyethyleneimine (PEI)-coated IONPs exhibited significantly higher uptake than PEGylated ones in both macrophages and cancer cells and caused severe cytotoxicity through multiple mechanisms such as ROS production and apoptosis. In that respect, replacing PEI with a biocompatible poly-L-lysine coating also bearing positive charge may solve the problem [28].

\section{Conclusions: Advantages, Disadvantages, and Future Challenges}

Emerging nanotechnologies provide new perspectives in medicine for solving challenging problems caused by complex human diseases such as neoplasia and debilitating neurodegenerative diseases. In particular, novel applications of magnetic nanoparticles in nanomedicine now involve MNPs in a variety of tasks, such as medical imaging, controlled drug and gene delivery, drug distribution, mitigating the side effects and multiple drug resistance, as well as the aid the MNPs provide in the invasive medical interventions. The advantages of nanotechnologies based on magnetic nanoparticles include the unique electromagnetic and magneto-mechanical properties of MNPs allowing for communication and controlling of their vibration, rotation and translational movement, absorption of electromagnetic energy, and remote heating and actuation. The deep penetration of magnetic fields through living tissues without any effect on healthy cells is a great attribute. The possibility of surface functionalization provides the feasibility to accumulate MNPs at specific locations, e.g., in cancer cells, and enables destruction of the targeted cells by releasing chemotherapeutic drugs, nucleic acids for gene therapy, or a disruption of the cytoskeletal framework of the cell on a remote command. The MNP-based imaging is becoming one of the most versatile imaging techniques with its high spatial and temporal resolution and can serve for cancer diagnosing and grading, and to guide surgical interventions. The MNPs are generally biocompatible and relatively stable, especially when protected by a dense self-assembling monolayer or by coating with a shell of gold, silica, or carbons. A great advantage of MNPs is the feasibility of attaching them to targeted cells that permits cell sorting, e.g., removal of circulating tumor cells or collecting them for analysis. The disadvantages of common 
MNPs are mainly related to their weak magnetic properties and the requirement of large size particles, especially when applied in hyperthermia treatment (usually for SPION, particle diameter should be $>250 \mathrm{~nm}[74,93])$ and the large size creates then problems with their retrieval from the body. Since the hyperthermia involves larger area of the tissue due to the high thermal conductivity of water and thus encases also healthy cells, this procedure is less likely to be at the forefront of MNP-based technologies. On the other hand, the theranostic, controlled drug release and magneto-mechanical disruption of cytoskeletal framework of cancer cells, as well as the lysosomal membrane permeabilization processes are likely to be among the favorite development strategies.

Future challenges will certainly involve the development of smaller superparamagnetic NPs with stronger magnetic responsivity to maintain the high spatial and temporal sensitivity for the emerging magnetic particle imaging (MPI) technology while enabling an enhanced renal clearance (NP diameter $\sim 2 \mathrm{~nm}$ or less). Further development of the new MPI technology and its application for whole-body scanning will enable radiation-free tomographic monitoring of medical interventions, tumorigenesis, and therapeutic outcomes. Extensive research will be needed to develop rapid and convenient microfluidic techniques for the challenging detection of circulating tumor cells, cell sorting, and sensor arrays ( $\mu$ PADs) for testing sets of cancer biomarkers to enable reliable cancer diagnostics and monitoring of cancer therapy at points-of-care with high efficacy. The use of MNPs in development of these analytical devices ( $\mu$ PADs, biosensors, lateral flow sensors, etc.) is crucial as it allows for rapid handling of NPs and separation of MNP-labelled CTCs.

Funding: This research received no external funding.

Conflicts of Interest: The authors declare no conflict of interest.

\section{References}

1. Graeser, M.; Thieben, F.; Szwargulski, P.; Werner, F.; Gdaniec, N.; Boberg, M.; Griese, F.; Moddel, M.; Ludewig, P.; van de Ven, D.; et al. Human-sized magnetic particle imaging for brain applications. Nat. Commun. 2019, 10, 1936. [CrossRef] [PubMed]

2. Vogel, P.; Markert, J.; Ruckert, M.A.; Herz, S.; Kessler, B.; Dremel, K.; Althoff, D.; Weber, M.; Buzug, T.M.; Bley, T.A.; et al. Magnetic particle imaging meets computed tomography: First simultaneous imaging. Sci. Rep. 2019, 9, 12627. [CrossRef] [PubMed]

3. Gobbo, O.L.; Sjaastad, K.; Radomski, M.W.; Volkov, Y.; Prina-Mello, A. Magnetic nanoparticles in cancer theranostics. Theranostics 2015, 5, 1249-1263. [CrossRef] [PubMed]

4. Bakshi, S.; Zakharchenko, A.; Mino, S.; Kolpashchikov, D.M.; Katz, E. Towards nanomaterials for cancer theranostics: A system of DNA-modified magnetic nanoparticles for detection and suppression of RNA marker in cancer cells. Magnetochemistry 2019, 5, 24. [CrossRef]

5. Bakshi, S.F.; Guz, N.; Zakharchenko, A.; Deng, H.; Tumanov, A.V.; Woodworth, C.D.; Minko, S.; Kolpashchikov, D.M.; Katz, E. Magnetic field-activated sensing of mRNA in living cells. J. Am. Chem. Soc. 2017, 139, 12117-12120. [CrossRef]

6. Ilkhani, H.; Hughes, T.; Li, J.; Zhong, C.J.; Hepel, M. Nanostructured SERS-electrochemical biosensors for testing of anticancer drug interactions with DNA. Biosens. Bioelectron. 2016, 80, 257-264. [CrossRef]

7. Li, J.; Skeete, Z.; Shan, S.; Yan, S.; Kurzatkowska, K.; Zhao, W.; Ngo, Q.M.; Holubovska, P.; Luo, J.; Hepel, M.; et al. Surface Enhanced Raman Scattering Detection of Cancer Biomarkers with Bifunctional Nanocomposite Probes. Anal. Chem. 2015, 87, 10698-10702. [CrossRef]

8. Santiago, T.; DeVaux, R.S.; Kurzatkowska, K.; Espinal, R.; Herschkowitz, J.I.; Hepel, M. Surface-enhanced Raman scattering investigation of targeted delivery and controlled release of gemcitabine. Int. J. Nanomed. 2017, 12, 7763-7776. [CrossRef]

9. Ratajczak, K.; Krazinski, B.E.; Kowalczyk, A.E.; Dworakowska, B.; Jakiela, S.; Stobiecka, M. Hairpin-Hairpin Molecular Beacon Interactions for Detection of Survivin mRNA in Malignant SW480 Cells. ACS Appl. Mater. Interfaces 2018, 10, 17028-17039. [CrossRef] 
10. Stobiecka, M.; Dworakowska, B.; Jakiela, S.; Lukasiak, A.; Chalupa, A.; Zembrzycki, K. Sensing of Survivin mRNA in Malignant Astrocytes Using Graphene Oxide Nanocarrier-Supported Oligonucleotide Molecular Beacons. Sens. Actuators B 2016, 235, 136-145. [CrossRef]

11. Uzek, R.; Sari, E.; Merkoci, A. Optical-based (bio) sensing systems using magnetic nanoparticles. Magnetochemietry 2019, 5, 59. [CrossRef]

12. Ferrari, M. Cancer nanotechnology: Opportunities and challenges. Nat. Rev. Cancer 2005, 5, 161-171. [CrossRef] [PubMed]

13. Allen, T.M. Ligand-targeted therapeutics in anticancer therapy. Nat. Rev. Drug Discov. 2002, 2, 750-763. [CrossRef] [PubMed]

14. Park, H.Y.; Schadt, M.J.; Wang, L.; Lim, I.I.S.; Njoki, P.N.; Kim, S.H.; Jang, M.Y.; Luo, J.; Zhong, C.J. Fabrication of magnetic core@shell Fe oxide @Au nanoparticles for interfacial bioactivity and bio-separation. Langmuir 2007, 23, 9050-9056. [CrossRef]

15. Skeete, Z.; Cheng, H.; Crew, E.; Lin, L.; Zhao, W.; Joseph, P.; Shan, S.; Cronk, H.; Luo, J.; Zhang, Q.; et al. Design of functional nanoparticles and assemblies for theranostic applications. ACS Appl. Mater. Interface 2014, 6, 21752-21768. [CrossRef]

16. Oyewumi, M.O.; Mumper, R.J. Comparison of cell uptake, biodistribution and tumor retention of folate-coated and PEG-coated gadolinium nanoparticles in tumor-bearing mice. J. Control. Release 2004, 95, 613-626. [CrossRef]

17. Hufschmid, R.; Landers, J.; Shasha, C.; Salamon, S.; Wende, H.; Krishnan, K.M. Nanoscale physical and chemical structure of iron oxide nanoparticles for magnetic particle imaging. Phys. Status Solidi A 2018. [CrossRef]

18. Bergey, E.J.; Levy, L.; Wang, X.; Krebs, L.J.; Lal, M.; Kim, K.S.; Pakatchi, S.; Liebow, C.; Prasad, P.N. DC Magnetic Field Induced Magnetocytolysis of Cancer Cells Targeted by LH-RH Magnetic Nanoparticles in vitro. Biomed. Microdev. 2002, 4, 293-299. [CrossRef]

19. Kemp, S.J.; Ferguson, R.M.; Khandhar, A.P.; Krishnan, K.M. Monodisperse magnetite nanoparticles wit nearly ideal saturation magnetization. RSC Adv. 2016, 6, 77452-77464. [CrossRef]

20. Liu, Y.; Chi, Y.; Shan, S.; Yin, J.; Luo, J.; Zhong, C.J. Characterization of magnetic NiFe nanoparticles with controlled bimetallic composition. J. Alloys Compd. 2014, 587, 260-266. [CrossRef]

21. Ziemian, S.; Lowa, N.; Kosch, O.; Bajj, D.; Wiekhorst, F.; Schutz, G. Optimization of iron oxide tracer synthesis for magnetic particle imaging. Nanomaterials 2018, 8, 180. [CrossRef] [PubMed]

22. Bao, N.; Shen, L.; Wang, Y.; Padhan, P.; Gupta, A. $\mathrm{Fe}_{3} \mathrm{O}_{4}$ superparamagnetic size 19.8 nm. J. Am. Chem. Soc. 2007, 129, 12374. [CrossRef] [PubMed]

23. Yan, F.; Kopelman, R.; Reddy, R. Synthesis and characterization of silica-embedded iron oxide nanoparticles for magnetic resonance imaging. J. Nanosci. Nanotechnol. 2004, 4, 72-76. [CrossRef]

24. Skeete, Z.; Cheng, H.W.; Li, J.; Salazar, C.; Sun, W.; Ngo, Q.M.; Lin, L.; Luo, J.; Zhong, C.J. Assessing Interparticle Spatial Characteristics of DNA-Linked Core-Shell Nanoparticles with or without Magnetic Cores in Surface Enhanced Raman Scattering. J. Phys. Chem. C 2017, 121, 15767-15776. [CrossRef]

25. Zhang, Y.; Shang, M. Self-assembled coatings on individual monodisperse magnetite nanoparticles for efficient intracellular uptake. Biomed. Microdev. 2004, 6, 33-40. [CrossRef]

26. Kydd, J.; Jadia, R.; Velpurisiva, O.; Gad, A.; Pallwal, S.; Rai, P. Targeting strategies for the combination treatment of cancer using drug delivery systems. Pharmaceutics 2017, 9, 46. [CrossRef]

27. Smith, M.; Hepel, M. Controlled release of targeted anti-leukemia drugs azacitidine and decitabine monitored using surface-enhanced Raman scattering (SERS) spectroscopy. Mediterr. J. Chem. 2017, 6, 125-132. [CrossRef]

28. Stobiecka, M.; Hepel, M. Double-shell gold nanoparticle-based DNA-carriers with poly-L-lysine binding surface. Biomaterials 2011, 32, 3312-3321. [CrossRef]

29. Krishnan, S.; Goud, K.Y. Magnetic particle bioconjugates: A versatile sensor approach. Magnetochemistry 2019, 5, 64. [CrossRef]

30. Lakowicz, J.R.; Ray, K.; Chowdhury, M.; Szmacinski, H.; Fu, Y.; Zhang, J.; Nowaczyk, K. Plasmon-controlled fluorescence: A new paradigm in fluorescence spectroscopy. Analyst 2008, 133, 1308-1346. [CrossRef]

31. Ray, K.; Chowdhury, M.H.; Zhang, J.; Fu, Y.; Szmacinski, H.; Nowaczyk, K.; Lakowicz, J.R. Plasmon-controlled fluorescence towards high-sensitivity optical sensing. Adv. Biochem. Engng. Biotechnol. 2009, 116, $29-72$.

32. Xie, F.; Pang, J.S.; Centeno, A.; Ryan, M.P.; Riley, D.J.; Alford, N.M. Nanoscale control of Ag nanostructures for plasmonic fluorescence enhancement of near-infrared dyes. Nano Res. 2013, 6, 496-510. [CrossRef] 
33. Zheng, Y.B.; Kiraly, B.; Weiss, P.S.; Huang, T.J. Molecular plasmonics for biology and nanomedicine. Nanomedicine 2012, 751-770. [CrossRef] [PubMed]

34. Aroca, R.F.; Teo, G.Y.; Mohan, H.; Guerrero, A.R.; Albella, P.; Moreno, F. Plasmon-Enhanced Fluorescence and Spectral Modification in SHINEF. J. Phys. Chem. C 2011, 115, 20419-20424. [CrossRef]

35. Feng, A.L.; You, M.L.; Tian, L.; Singamaneni, S.; Liu, M.; Duan, Z.; Lu, T.J.; Xu, F.; Lin, M. Distance-Dependent Plasmon-Enhanced Fluorescence of Upconversion Nanoparticles using Polyelectrolyte Multilayers as Tunable Spacers. Sci. Rep. 2015, 5, 7779. [CrossRef] [PubMed]

36. Stobiecka, M. Novel plasmonic field-enhanced nanoassay for trace detection of proteins. Biosens. Bioelectron. 2014, 55, 379-385. [CrossRef]

37. Stobiecka, M.; Chalupa, A. Modulation of Plasmon-Enhanced Resonance Energy Transfer to Gold Nanoparticles by Protein Survivin Channeled-Shell Gating. J. Phys. Chem. B 2015, 119, 13227-13235. [CrossRef]

38. $\mathrm{Xu}, \mathrm{H}$.; Wallace, R.; Hepel, M. Interactions of antifouling monolayers: Energy transfer from excitedalbumin molecule to phenol red dye. Chem. Pap. 2015, 69, 227-236. [CrossRef]

39. Ratajczak, K.; Lukasiak, A.; Grel, H.; Dworakowska, B.; Jakiela, S.; Stobiecka, M. Monitoring of dynamic ATP level changes by oligomycin-modulated ATP synthase inhibition in SW480 cancer cells using fluorescent “On-Off" switching DNA aptamer. Anal. Bioanal. Chem. 2019, 411, 6899-6911. [CrossRef]

40. Stobiecka, M.; Hepel, M. Rapid functionalization of metal nanoparticles by moderator-tunable ligand-exchange process for biosensor designs. Sens. Actuators B 2010, 149, 373-380. [CrossRef]

41. Hepel, M.; Stobiecka, M. Detection of Oxidative Stress Biomarkers Using Functional Gold Nanoparticles. In Fine Particles in Medicine and Pharmacy; Matijević, E., Ed.; Springer: Boston, MA, USA, 2012; pp. 241-281.

42. Hutter, E.; Maysinger, D. Gold-nanoparticle-based biosensors for detection of enzyme activity. Trends Pharmacol. Sci. 2013, 34, 497-507. [CrossRef] [PubMed]

43. Bakshi, S.F.; Guz, N.; Zakharchenko, A.; Deng, H.; Tumanov, A.V.; Woodworth, C.D.; Minko, S.; Kolpashchikov, D.M.; Katz, E. Nanoreactors Based on DNAzyme-Functionalized Magnetic Nanoparticles Activated by Magnetic Field. Nanoscale 2018, 10, 1356-1365. [CrossRef] [PubMed]

44. He, Y.; Chen, S.; Huang, L.; Wang, Z.; Wu, Y.; Fu, F. Combination of Magnetic-Beads-Based Multiple Metal Nanoparticles Labeling with Hybridization Chain Reaction Amplification for Simultaneous Detection of Multiple Cancer Cells with Inductively Coupled Plasma Mass Spectrometry. Anal. Chem. 2019, 91, 1171-1177. [CrossRef] [PubMed]

45. Kolosnjaj-Tabi, J.; Wilhelm, C.; Clement, O.; Gazeau, F. Cell labelling with magnetic nanoparticls: Opportunity for magnetic cell imaging and cell manipulation. J. Nanobiotechnol. 2013, 11, S7. [CrossRef] [PubMed]

46. Huang, W.; Chang, C.L.; Chan, B.D.; Jalal, S.I.; Matei, D.E.; Low, P.S.; Savran, C.A. Concurrent detection of cellular and molecular cancer markers using an immunomagnetic flow system. Anal. Chem. 2015, 87, 10205-10212. [CrossRef] [PubMed]

47. Ratajczak, K.; Krazinski, B.E.; Kowalczyk, A.E.; Dworakowska, B.; Jakiela, S.; Stobiecka, M. Optical biosensing system for the detection of survivin mRNA in colorectal cancer cells using a graphene oxide carrier-bound oligonucleotide molecular beacon. Nanomaterials 2018, 8, 510. [CrossRef]

48. Running, L.; Espinal, R.; Hepel, M. Controlled release of targeted chemotherapeutic drug dabrafenib for melanoma cancers monitored using surface-enhanced Raman scattering (SERS) spectroscopy. Mediterr. J. Chem. 2018, 7, 18-27. [CrossRef]

49. Hepel, M.; Stobiecka, M. Interactions of Herbicide Atrazine with DNA; Nova Science Publishers: New York, NY, USA, 2010; ISBN 978-1-6172-8908-8.

50. Kamaly, N.; Yameen, B.; Wu, J.; Farokhzad, O.C. Degradable controlled release polymers and polymeric nanoparticles: Mechanisms of controlling drug release. Chem. Rev. 2016, 116, 2602-2663. [CrossRef]

51. Wong, P.T.; Choi, S.K. Mechanisms of drug release in nanotherapeutic delivery systems. Chem. Rev. 2015, 115, 3388-3432. [CrossRef]

52. Hong, R.; Han, G.; Fernández, J.M.; Kim, B.J.; Forbes, N.S.; Rotello, V.M. Glutathione-mediated delivery and release using monolayer protected nanoparticle carriers. J. Am. Chem. Soc. 2006, 128, 1078-1079. [CrossRef]

53. Mosayebi, J.; Kiyasatfar, M.; Laurent, S. Synthesis, functionalization, and design of magnetic nanoparticles for theranostic applications. Adv. Healthc. Mater. 2017, 6, 1700306. [CrossRef]

54. McBain, S.C.; Yiu, H.H.P.; Dobson, J. Magnetic nanoparticles for gene and drug delivery. Int. J. Nanomed. 2008, 3, 169-180. 
55. Gul, S.; Khan, S.B.; Rehman, I.U.; Khan, M.A.; Khan, M.I. A comprehensive review of magnetic nanomaterials modern day theranostics. Front. Mater. 2019, 6, 179. [CrossRef]

56. Latorre, A.; Couleaud, P.; Aires, A.; Cortajarena, A.L.; Somoza, A. Multifunctionalization of magnetic nanoparticles for controlled drug release: A general approach. Eur. J. Med. Chem. 2014, 82, 355-362. [CrossRef]

57. Zhao, J.; Wu, S.; Qin, J.; Shi, D.; Wang, Y. Electrical-Charge-Mediated Cancer Cell Targeting via Protein Corona-Decorated Superparamagnetic Nanoparticles in a Simulated Physiological Environment. ACS Appl. Mater. Interfaces 2018, 10, 41986-41998. [CrossRef]

58. Connell, J.J.; Patrick, P.S.; Yu, Y.; Lythgoe, M.F.; Kalber, T.L. Advanced cell therapies: Targeting, tracking and actuation of cells with magnetic particles. Regenerat. Med. 2015, 10, 757-772. [CrossRef]

59. Gleich, B.; Weizenecker, J. Tomographic imaging using the nonlinear response of magnetic particles. Nature 2005, 435, 1214. [CrossRef]

60. Herz, S.; Vogel, P.; Dietrich, P.; Kampf, T.; Ruckert, M.A.; Kickuth, R.; Behr, V.C.; Bley, T.A. Magnetic particle imaging guided real-time percutaneous transluminal angioplasty in a phantom model. Cardiovasc. Intervent. Radiol. 2018. [CrossRef]

61. Herz, S.; Vogel, P.; Kampf, T.; Dietrich, P.; Veldhoen, S.; Ruckert, M.A.; Kickuth, R.; Behr, V.C.; Bley, T.A. Magnetic particle imaging-guided stenting. J. Endovasc. Ther. 2019, 26, 512-519. [CrossRef]

62. Weller, A.; Salamon, J.M.; Frolich, A.; Moddel, M.; Knopp, T.; Werner, R. Combining direct 3D volume rendering and magnetic particle imaging to advance radiation-free real-time 3D guidance of vascular interventions. Cardiovasc. Intervent. Radiol. 2019. [CrossRef]

63. Vogel, P.; Ruckert, M.A.; Kemp, S.J.; Khandhar, A.P.; Ferguson, R.M.; Herz, S.; Vilter, A.; Klauer, P.; Bley, T.A.; Krishnan, K.M.; et al. Micro-traveling wave magnetic particle imaging-sub-millimeter resolution with optimized tracer LS-008. IEEE Trans. Magnet. 2019. [CrossRef]

64. Molwitz, I.; Ittrich, H.; Knopp, T.; Mummert, T.; Jung, J.S.C.; Adam, G.; Kaul, M.G. First magnetic particle imaging angiography in human sized organs by employing a multimodal ex vivo pig kidney perfusion system. Physiol. Meas. 2019. [CrossRef] [PubMed]

65. Talebloo, N.; Gudi, M.; Robertson, N.; Wang, P. Magnetic particle imaging: Current applications in biomedical research. J. Magnet. Resonace Imag. 2019. [CrossRef] [PubMed]

66. Shasha, C.; Teeman, E.; Krishnan, K.M. Nanoparticle core size optimization for magnetic particle imaging. Biomed. Phys. Engng. Expr. 2019. [CrossRef]

67. Teeman, E.; Shasha, C.; Evans, J.E.; Krishnan, K.M. Intracellular dynamics of superparamagnetic iron oxide nanoparticles for magnetic particle imaging. Nanoscale 2019. [CrossRef] [PubMed]

68. Yu, E.Y.; Bishop, M.; Zheng, B.; Ferguson, R.M.; Khandhar, A.P.; Kemp, S.J.; Krishnan, K.M.; Goodwill, P.W.; Conolly, S.M. Magnetic Particle Imaging: A Novel in Vivo Imaging Platform for Cancer Detection. Nano Lett. 2017, 17, 1648-1654. [CrossRef]

69. Bagheri, H.; Kierans, C.A.; Nelson, K.J.; Andrade, B.A.; Wong, C.L.; Frederick, A.L.; Hayden, M.E. A mechanically driven magnetic particle imaging scanner. Appl. Phys. Lett. 2018, 113, 183703. [CrossRef]

70. Bakenecker, A.C.; Ahiborg, M.; Debbeler, C.; Kaethner, C.; Buzug, T.M.; Ludtke-Buzug, K. Magnetic particle imaging in vascular medicine. Innov. Surg. Sci. 2018, 3, 179-192.

71. Bartorelli, A.L.; Marenzi, G. Contrast-induced nephropathy. J. Interv. Cardiol. 2008, 21, 74-85. [CrossRef]

72. Schlorf, T.; Meincke, M.; Kossel, E.; Glüer, C.C.; Jansen, O.; Mentlein, R. Biological properties of iron oxide nanoparticles for cellular and molecular magnetic resonance imaging. Int J. Mol. Sci. 2010, 12, 12-23. [CrossRef]

73. Vallejo-Fernandez, G.; Whear, O.; Roca, A.G.; Hussain, S.; Timmis, J.; Patel, V.; O'Grady, K. Mechanisms of hyperthermia in magnetic nanoparticles. J. Phys. D Appl. Phys. 2013, 46, 312001. [CrossRef]

74. Carrey, J.; Mehdaoui, B.; Respaud, M. Simple models for dynamic hysteresis loop calculations of magnetic single-domain nanoparticles: Application to magnetic hyperthermia optimization. J. Appl. Phys. 2011, 109, 083921. [CrossRef]

75. Lachowicz, D.; Kaczyńska, A.; Wirecka, R.; Kmita, A.; Szczerba, W.; Bodzoń-Kułakowska, A.; Sikora, M.; Karewicz, A.; Zapotoczny, S. A hybrid system for magnetic hyperthermia and drug delivery: SPION functionalized by curcumin conjugate. Materials 2018, 11, 2388. [CrossRef] [PubMed] 
76. Drašler, B.; Drobne, D.; Novak, S.; Valant, J.; Boljte, S.; Otrin, L.; Rappolt, M.; Sartori, B.; Iglič, A.; Kralj-Iglič, V.; et al. Effects of magnetic cobalt ferrite nanoparticles on biological and artificial lipid membranes. Int. J. Nanomed. 2014, 9, 1559-1581. [CrossRef] [PubMed]

77. Verde, E.L.; Landi, G.T.; Gomes, J.A.; Sousa, M.H.; Bakuzis, A.F. Magnetic hyperthermia investigation of cobalt ferrite nanoparticles: Comparison between experiment, linear response theory, and dynamic hysteresis simulations. J. Appl. Phys. 2012, 111. [CrossRef]

78. Hilger, I. In vivo applications of magnetic nanoparticle hyperthermia. Int. J. Hyperthermia 2013, $29,828-834$. [CrossRef]

79. Sun, J.; Guo, M.; Pang, H.; Qi, J.; Zhang, J.; Ge, Y. Treatment of malignant glioma using hyperthermia. Neural Regen. Res. 2013, 8, 2775-2782.

80. Wu, F.; Sun, B.; Chu, X.; Zhang, Q.; She, Z.; Song, S.; Zhou, N.; Zhang, J.; Yi, X.; Wu, D.; et al. Hyaluronic Acid-Modified Porous Carbon-Coated $\mathrm{Fe}_{3} \mathrm{O}_{4}$ Nanoparticles for Magnetic Resonance Imaging-Guided Photothermal/Chemotherapy of Tumors. Langmuir 2019, 35, 13135-13144. [CrossRef]

81. Wu, F.; Zhang, M.; Lu, H.; Liang, D.; Huang, Y.; Xia, Y.; Hu, Y.; Hu, S.; Wang, J.; Yi, X.; et al. Triple Stimuli-Responsive Magnetic Hollow Porous Carbon-Based Nanodrug Delivery System for Magnetic Resonance Imaging-Guided Synergistic Photothermal/Chemotherapy of Cancer. ACS Appl. Mater. Interfaces 2018, 10, 21939-21949. [CrossRef]

82. Lee, S.M.; Kim, H.J.; Kim, S.Y.; Kwon, M.K.; Kim, S.; Cho, A.; Yun, M.; Shin, J.S.; Yoo, K.H. Drug-loaded gold plasmonic nanoparticles for treatment of multidrug resistance in cancer. Biomaterials 2014, 35, 2272-2282. [CrossRef]

83. Bar-Zeev, M.; Livney, Y.D.; Assaraf, Y.G. Targeted nanomedicine for cancer therapeutics: Towards precision medicine overcoming drug resistance. Drug Resist. Updates 2017, 31, 15-30. [CrossRef] [PubMed]

84. Mazon, E.E.; Samano, A.H.; Calleja, H.; Quintero, L.H.; Paz, J.A.; Cano, M.E. A frequency tuner for resonant inverters suitable for magnetic hyperthermia applications. Meas. Sci. Technol. 2017, 28, 095901. [CrossRef]

85. Villanueva, A.; Presa, P.d.l.; Alonso, J.M.; Rueda, T.; Martınez, A.; Crespo, P.; Morales, M.P.; Gonzalez-Fernandez, M.A.; Valdes, J.; Rivero, G. Hyperthermia HeLa cell treatment with silica-coated manganese oxide nanoparticles. J. Phys. Chem. C 2010, 114, 1976-1981. [CrossRef]

86. Creixell, M.; Bohorquez, A.C.; Torres-Lugo, M.; Rinaldi, C. EGFR-targeted magnetic nanoparticle heaters kill cancer cells without a perceptible temperature rise. ACS Nano 2011, 5, 7124-7129. [CrossRef]

87. Domenech, M.; Marrero-Berrios, I.; Torres-Lugo, M.; Rinaldi, C. Lysosomal membrane permeabilization by targeted magnetic nanoparticles in alternating magnetic fields. ACS Nano 2013, 7, 5091-5101. [CrossRef]

88. Sanchez, C.; Diab, D.E.H.; Connord, V.; Clerc, P.; Meunier, E.; Pipy, B.; Fourmy, D. Targeting a G-protein-coupled receptor overexpressed in endocrine tumors by magnetic nanoparticles to induce cell death. ACS Nano 2014, 8, 1350-1363. [CrossRef]

89. Zhang, E.; Kircher, M.F.; Koch, X.M.; Eliasson, L.; Goldberg, S.N.; Renstrom, E. Dynamic magnetic fields remote-control apoptosis via nanoparticle rotation. ACS Nano 2014, 8, 3192-3201. [CrossRef]

90. Connord, V.; Clerc, P.; Hallali, N.; Diab, D.E.H.; Fourmy, D.; Gigoux, V.; Carrey, J. Real-time analysis of magnetic hyperthermia experiments on living cells under a confocal microscope. Small 2015, 11, 2437-2445. [CrossRef]

91. Klyachko, N.L.; Sokolsky-Papkov, M.; Pothayee, N.; Efremova, M.V.; Gulin, D.A.; Pothayee, N.; Kuznetsov, A.A.; Majouga, A.G.; Riffle, J.S.; Golovin, Y.I.; et al. Changing the enzyme reaction rate in magnetic nanosuspensions by a non-heating magnetic field. Angew. Chem. Int. Ed. 2012, 51, 12016-12019. [CrossRef]

92. Kim, D.H.; Rozhkova, E.A.; Ulasov, I.V.; Bader, S.D.; Rajh, T.; Lesniak, M.S.; Novosad, V. Biofunctionalized magnetic-vortex microdiscs for targeted cancer-cell destruction. Nat. Mater. 2010, 9, 165-171. [CrossRef]

93. Master, A.M.; Williams, P.N.; Pothayee, N.; Pothayee, N.; Zhang, R.; Vishwasrao, H.M.; Golovin, Y.I.; Riffle, J.S.; Sokolsky, M.; Kabanov, A.V. Remote actuation of magnetic nanoparticles for cancer cell selective treatment through cytoskeletal disruption. Sci. Rep. 2016, 6, 33560. [CrossRef] [PubMed]

94. Hoffmann, C.; Mazari, E.; Lallet, S.; Borgne, R.L.; Marchi, V.; Gosse, C.; Gueroui, Z. Spatiotemporal control of microtubule nucleation and assembly using magnetic nanoparticles. Nat. Nanotechnol. 2013, 8, 199-205. [CrossRef] [PubMed] 
95. Dixon, S.J.; Lemberg, K.M.; Lamprecht, M.R.; Skouta, R.; Zaitsev, E.M.; Gleason, C.E.; Patel, D.N.; Bauer, A.J.; Cantley, A.M.; Yang, W.S.; et al. Ferroptosis: An iron-dependent form of nonapoptotic cell death. Cell 2012, 149, 1060-1072. [CrossRef] [PubMed]

96. Dixon, S.J.; Stockwell, B.R. The role of iron and reactive oxygen species in cell death Scott J Dixon1, $5^{*} \&$ Brent R Stockwell. Nat. Chem. Biol. 2014, 10, 9-17. [CrossRef] [PubMed]

97. Tan, S.; Schubert, D.; Maher, P. Oxytosis: A novel form of programmed cell death. Curr. Top. Med. Chem. 2001, 1, 497-506. [CrossRef]

98. Trachootham, D.; Alexandre, J.; Huang, P. Targeting cancer cells by ROS-mediated mechanisms: A radical therapeutic approach? Nat. Rev. Drug Discov. 2009, 8, 579-591. [CrossRef]

99. Prasad, S.; Gupta, S.C.; Tyagi, A.K. Reactive oxygen species (ROS) and cancer: Role of antioxidative nutraceuticalas. Cancer Lett. 2017, 387, 95-105. [CrossRef]

100. Wang, N.; Wu, Y.; Bian, J.; Qian, X.; Lin, H.; Sun, H.; You, Q.; Zhang, X. Current development of ROS-modulating agents as novel antitumor therapy. Curr. Cancer Drug Targets 2017, 17, 122-136. [CrossRef]

101. Shen, Z.; Song, J.; Yung, B.C.; Zhou, Z.; Wu, A.; Chen, X. Emerging strategies of cancer therapy based on ferroptosis. Adv. Mater. 2018, 30, 1704007. [CrossRef]

102. Hepel, M.; Stobiecka, M.; Peachey, J.; Miller, J. Intervention of glutathione in pre-mutagenic catechol-mediated DNA damage in the presence of copper(II). Mutat. Res. 2012, 735, 1-11. [CrossRef]

103. Yu, J.; Zhao, F.; Gao, W.; Yang, X.; Ju, Y.; Zhao, L.; Guo, W.; Xie, J.; Liang, X.; Tao, X.; et al. Magnetic Reactive Oxygen Species Nanoreactor for Switchable Magnetic Resonance Imaging Guided Cancer Therapy Based on pH-Sensitive $\mathrm{Fe}_{5} \mathrm{C}_{2} @ \mathrm{Fe}_{3} \mathrm{O}_{4}$ Nanoparticles. ACS Nano 2019, 13, 10002-10014. [CrossRef] [PubMed]

104. Hepel, M.; Stobiecka, M. Comparative kinetic model of fluorescence enhancement in selective binding of monochlorobimane to glutathione. J. Photochem. Photobiol. A Chem. 2011, 225, 72-80. [CrossRef]

105. Hepel, M.; Stobiecka, M. Supramolecular interactions of oxidative stress biomarker glutathione with fluorone black. Spectrochim. Acta A 2018, 192, 146-152. [CrossRef] [PubMed]

106. Hong, J.W.; Quake, S.R. Integrated nanoliter systems. Nat. Biotechnol. 2003, 21, 1179-1183. [CrossRef] [PubMed]

107. Green, B.J.; Nguyen, V.; Atenafu, E.; Weeber, P.; Duong, B.T.V.; Thiagalingam, P.; Labib, M.; Mohamadi, R.M.; Hansen, A.R.; Joshua, A.M.; et al. Phenotypic Profiling of Circulating Tumor Cells in Metastatic Prostate Cancer Patients Using Nanoparticle-Mediated Ranking. Anal. Chem. 2019, 91, 9348-9355. [CrossRef] [PubMed]

108. Mandal, K.; Jana, D.; Ghorai, B.K.; Jana, N.R. AIEgen-Conjugated Magnetic Nanoparticles as Magnetic-Fluorescent Bioimaging Probes. ACS Appl. Nano Mater. 2019, 2, 3292-3299. [CrossRef]

109. Han, S.I.; Han, K.H. Electrical detection method for circulating tumor cells using graphene nanoplates. Anal. Chem. 2015, 87, 10585-10592. [CrossRef]

110. Wang, Z.; Sun, N.; Liu, H.; Chen, C.; Ding, P.; Yue, X.; Zou, H.; Xing, C.; Pei, R. High-Efficiency Isolation and Rapid Identification of Heterogeneous Circulating Tumor Cells (CTCs) Using Dual-Antibody-Modified Fluorescent-Magnetic Nanoparticles. ACS Appl. Mater. Interfaces 2019, 11, 39586-39593. [CrossRef]

111. Fang, C.; Zhang, M. Multifunctional magnetic nanoparticles for medical imaging applications. J. Mater. Chem. 2009, 19, 6258-6266. [CrossRef]

112. Feng, Q.; Liu, Y.; Huang, J.; Chen, K.; Huang, J.; Xiao, K. Uptake, distribution, clearance, and toxicity of iron oxide nanoparticles with different sizes and coatings. Sci. Rep. 2018, 8, 2082. [CrossRef]

(C) 2020 by the author. Licensee MDPI, Basel, Switzerland. This article is an open access article distributed under the terms and conditions of the Creative Commons Attribution (CC BY) license (http://creativecommons.org/licenses/by/4.0/). 